\title{
ARTHROSCOPIC AUTOLOGOUS OSTEOCHONDRAL MOSAICPLASTY FOR THE TREATMENT OF SUBCHONDRAL CYSTIC LESION IN THE MEDIAL FEMORAL CONDYLE IN A HORSE
}

\author{
G. Bodó ${ }^{1 *}$, L. HAnGOdY ${ }^{2}$, Zsuzsa Szabó ${ }^{3}$, CH. Peham ${ }^{4}$, Monika SCHINZeL $^{4}$, \\ D. GIRTLER ${ }^{4}$ and P. SÓTONYI ${ }^{5}$
}

\begin{abstract}
${ }^{1}$ Department and Clinic of Surgery and Ophthalmology and ${ }^{5}$ Department of Anatomy, Faculty of Veterinary Science, 'Szent István’ University, H-1400 Budapest, P.O. Box 2, Hungary; ${ }^{2}$ Orthopaedics and Trauma Department and ${ }^{3}$ Anaesthesiology and Intensive Care Unit, Uzsoki Hospital, Budapest, Hungary; ${ }^{4} \mathrm{Clinic}$ for Orthopaedics in Ungulates, University of Veterinary Medicine, Vienna, Austria
\end{abstract}

(Received December 18, 1999; accepted February 1, 2000)

An 11-year-old, Hungarian half-bred stallion was presented with a history of mixed left hindlimb lameness of 6 months duration. Subchondral bone cyst of the medial femoral condyle and injury of the medial meniscus were diagnosed. Osteochondral autograft transplantation (mosaic arthroplasty) was performed, taking grafts from the less weight-bearing medial border of the medial femoral trochlea of the affected limb, and transplanting them into the cyst during arthroscopy. The lameness was evaluated prior to and one year after the operation with a motion analysis system during treadmill exercise. Considerable improvement of the lameness and the clinical signs as well as successful transplantation of the grafts, and a new hard joint cartilage surface of the medial femoral condyle could be detected during follow-up arthroscopy. Osteochondral autograft transplantation seems to bee a possible alternative for treating subchondral cystic lesions of the medial femoral condyle in horses. A new technique for the surgical treatment of a subchondral cystic lesion of the medial femoral condyle in the horse is described.

Key words: Horse, subchondral cystic lesion, autograft transplantation, mosaicplasty

Subchondral cystic lesion of the medial femoral condyle develops in horses under 3 years of age (Jeffcott and Kold, 1982; Verschooten and De Moor, 1982; Jeffcott et al., 1983; Kold and Hickman, 1983, 1984; Stashak, 1987; Howard et al., 1995). Reports on conservative treatment mention a maximum of 50\% success after a 6-month period of rest following the initial diagnosis (Jeffcott and Kold, 1982; Verschooten and De Moor, 1982).

\footnotetext{
*E-mail: gbodo@univet.hu; Fax: +36 (1) 4784196
} 
Three different surgical techniques have been reported in the literature for healing subchondral cystic lesions of the medial femoral condyle in the horse.

The first method is performed by curetting the cystic cavity with sharp spoons and/or different arthroscopic burrs (Stewart and Reid, 1982; Stashak, 1987; White et al., 1988; McIlwraith, 1990; Howard et al., 1995). The results of this treatment are controversial. In a review of 41 cases treated arthroscopically, only $56 \%$ had a successful outcome, and in some of the unsuccessful cases the subchondral cystic lesion enlarged following surgery (Howard et al., 1995).

The second method involves packing of the curetted cystic cavity with autogenous, cancellous bone grafts taken from the contralateral tuber coxae (Evans and Jenny, 1970; Kold and Hickman, 1983, 1984; McIlwraith, 1990). Authors report a 60-70\% success rate (Kold and Hickman, 1983, 1984).

As a third method bone cement was used to fill the curetted cystic lesion (Hickman et al., 1984; Kold and Hickman, 1984). Advantage of this method is immediate support of the condyle, but side effects are that degenerative joint disease can develop when bone cement comes in direct contact with the opposing joint surface (Hickman et al., 1984).

The use of fresh, autogenous, cylindrical, osteochondral grafts for the treatment of focal chondral and osteochondral defects of the femoral condyles has been well described in human medicine (Matsusue et al., 1993; Hangody, 1994; Bobic, 1996; Hangody, 1997). This technique transplants multiple, smallsized, cylindrical osteochondral grafts harvested from the less weight-bearing patellofemoral periphery of the femoral condyles in a mosaic-like fashion.

The method aims at providing a hyaline-like resurfacement for small- and medium-sized focal chondral and osteochondral defects on the weight-bearing gliding surfaces. This procedure has been developed using several series of German Shepherd dog trials performed in the Department of Large Animal Surgery, University of Veterinary Science Budapest (Hangody et al., 1997a)

This case report describes the surgical treatment of a subchondral cystic lesion in the medial femoral condyle and medial meniscus damage of a horse. Surgery was indicated due to progressively deteriorating lameness, which became severe over a period of 4 months.

\section{Case history}

A 11-year-old Hungarian half-bred stallion was referred to the Department of Large Animal Surgery, University of Veterinary Science Budapest with a history of mixed hindlimb lameness, which was worsening during exercise. The horse had been lame for a 6-month period prior to this examination. As a 5-year-old, he had been lame in the same limb, but it was remedied with a few months of rest.

Veterinary inspection at the start of the lameness had revealed a mixed left hindlimb lameness, which did not change during exercise. At that time, the stal- 
lion had been in good condition and looked energetic. The horse had undergone a rest period for 4 months involving paddock exercise and phenylbutazone $2 \mathrm{mg} / \mathrm{kg} /$ day given orally during the first 6 weeks. The lameness had not improved under phenylbutazone; rather, it became worse than it had been at the beginning of the 4-month period. The horse was then brought to the clinic for detailed clinical examination.

By the time of our examination the stallion had lost about $100 \mathrm{~kg}$ bodyweight, did not want to trot of himself, and had lost his previous energetic appearance. Clinical examination revealed effusion in the femoropatellar and medial femorotibial joints. A grade 3 to 4 mixed lameness was present (scale 1-5). Especially in walk but also in trot a remarkable shortening of the cranial phase of the stride was visible. He showed exacerbation of the lameness following a hock-stifle flexion test. After negative perineural anaesthesia of the caudal tibial and both peroneal nerves, intraarticular anaesthesia of the medial femorotibial joint eliminated the lameness and the flexion test became negative. Lateromedial and caudocranial radiographic views revealed a large round-shaped subchondral bone cyst in the medial femoral condyle, which was communicating with the medial femorotibial joint via a narrow canal through the subchondral bone plate (Fig. 1A-B).
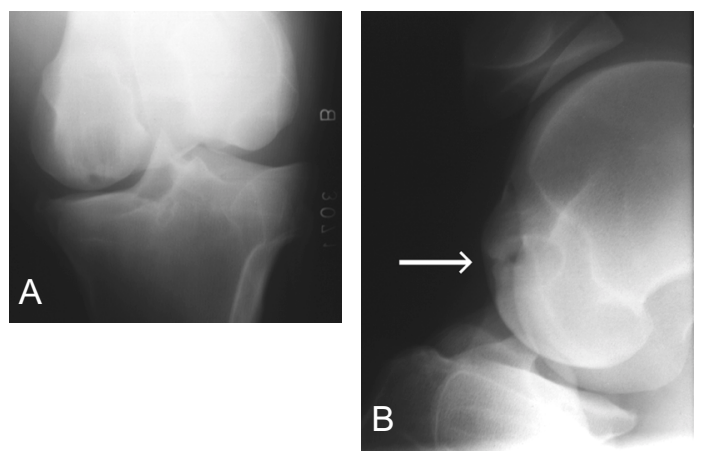

Fig. 1. A large, round-shaped cystic lesion can be seen in the medial femoral condyle, which communicates with the medial femorotibial joint via a narrow canal through the subchondral bone plate. A: caudocranial, B: lateromedial view

In caudocranial view, a large, irregularly outlined osteophyte formation was visible on the medial aspect of the medial tibial condyle, and considerable sclerosis around the cyst could be detected from both views.

The medial aspect of the medial femoral condyle also contained some irregularities on the surface. With the help of ultrasonography, rupture of the medial meniscus was detected.

The surgery was done at the Department of Large Animal Surgery, Faculty of Veterinary Science of the 'Szent István' University, Budapest, Hungary. 
Motion analysis was performed at the University of Veterinary Medicine, Clinic for Orthopaedics in Ungulates, Vienna, Austria.

\section{Surgical technique}

Theoretical considerations had been made during training on healthy cadaver stifle joints (and one cadaver stifle with a similar medial subchondral cystic lesion) prior to the operation. Those considerations established the decisions made during the transplantation according to the size and placement of the transplanted grafts.

Before surgery, water was given ad libitum and food was withheld for $12 \mathrm{~h} .2,000,000 \mathrm{U}$ benzathine penicillin, 500,000 $\mathrm{U}$ procaine penicillin and $3.1 \mathrm{~g}$ dihydrostreptomycin sulphate (Tardomyocel comp. III. inj., Bayer Hungaria Ltd., Budapest, Hungary) were given prior to surgery. The horse was anaesthetised and positioned in dorsal recumbency. The affected stifle was prepared for arthroscopic surgery.

For general arthroscopic examination of the medial femorotibial joint the standard lateral approach was used (McIlwraith, 1990). A depression in the articular surface indicated the connecting channel between the subchondral bone cyst and the joint (Fig. 3). Viewing that area, fibrillation of the hyaline cartilage around the depression was detected. Debridement of the inverted hyaline cartilage around the communicating channel was carried out prior to transplantation. The sharp cutting edge of the universal guide was used to determine the number of the necessary grafts to fill the defect as much as possible. The standard instrumentation involves 5 different sizes from 2.7 to $8.5 \mathrm{~mm}$ in diameter. The above-mentioned theoretical considerations suggested that the diameter of $6.5 \mathrm{~mm}$ could be the best choice. The method 'mosaic arthroplasty' described in human medicine (Hangody et al., 1997b) was adapted for the horse stifle. Instruments designed for the same purpose in human medicine were used (Fig. 2).

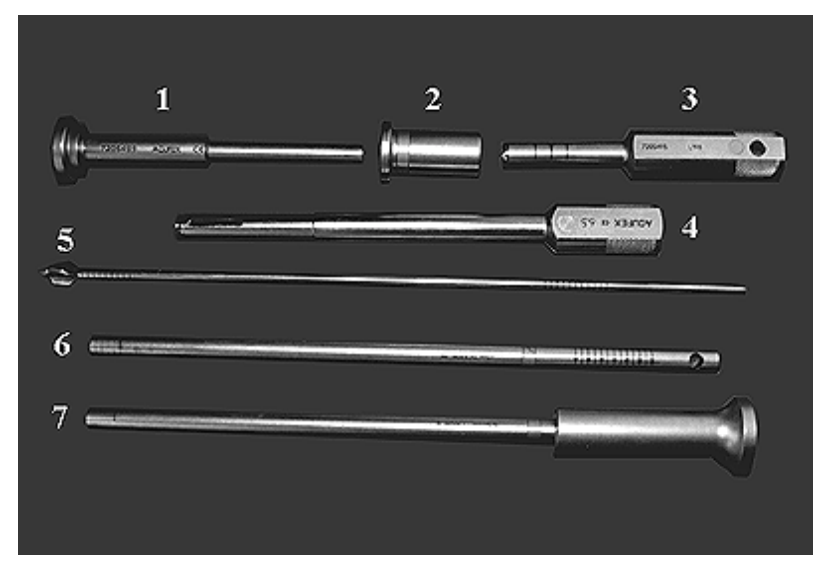

Fig. 2. Instruments designed for mosaic arthroplasty in human medicine were used. $1=$ harvesting tamp, $2=$ chisel guard, $3=$ tubular chisel, $4=$ universal drill guide, $5=$ drill bit for $6.5 \mathrm{~mm}$ grafts, $6=$ dilator, $7=$ delivery tamp 
Six pieces of $35-40 \mathrm{~mm}$ long, cylindrical, autologous, osteochondral grafts were taken under arthroscopic control from the dorsomedial aspect of the medial femoral trochlea with the help of a $6.5-\mathrm{mm}$ tubular chisel. The portal site was selected under arthroscopic control with a spinal needle to determine from which direction perpendicular access to the defect was possible. The stifle joint fully extended, we harvested the first graft from the most superior part of the donor area, flexing the limb always a bit more before taking the next graft, using the same portal for all six grafts. Preventing postoperative haemorrhage, biodegradable polyglyconate B plugs (Smith \& Nephew Inc. Andover, MA 01810 USA) were used to close the created holes (Fig. 4A).

During the second part of the operation, the stifle joint was held in full flexion (maximum angle of $90^{\circ}$ ). For the arthroscopic portal the same lateral approach was used as at the general examination of this joint. The portal was selected in the same manner as described previously. The placement of the first graft was chosen into the centre of the depression. An appropriately sized drill was put through the guide chisel to create a hole $40 \mathrm{~mm}$ in depth. After removing the drill, a tapered dilator was inserted $40 \mathrm{~mm}$ deep into the hole to create recipient tunnels of conical shape, providing the best press fit for the grafts during the rehabilitation period. During the last step of the procedure, the chisel guide was held firmly in place, the dilator removed and the graft delivered into the hole by the adjustable delivery tamp (Fig. 5). Through the windows of the guide, the desired depth of setting could be controlled while gently tapping down the graft by the delivery tamp. The further 5 grafts were inserted in a similar fashion around the first graft as close as possible to the previously implanted transplants.

Resection of the torn posterior flap of the medial meniscus was done during a second-look arthroscopy 4 months after the first surgery by motorised synovial resector (Smith \& Nephew Inc. Andover, MA 01810 USA) and Ferris Smith rongeurs (Smith \& Nephew Inc. Andover, MA 01810 USA) (Fig. 6), because of the lack of appropriate instrumentation at the time of the mosaicplasty. The donor sites could be recognised as smooth surfaces (without fibrillation or adhesion) with a circle-shaped formation indicating the top of the inserted polyglyconate plugs (Fig. 4B). The recipient area also looked regular, the transplanted cylindrical hyaline surfaces had slightly oval-shaped outline in caudocranial direction.

In human practice, the joint is drained for $24 \mathrm{~h}$, and a non-weight-bearing period with continuous passive motion is advised for $2-4$ weeks followed by a $2-$ week time of 30-40 kg partial loading (Hangody et al., 1997b). To achieve a partial-loading period neither drugs nor any other manipulation were administered to the horse except for the same antibiotics as before surgery, given for 5 days postoperatively. 


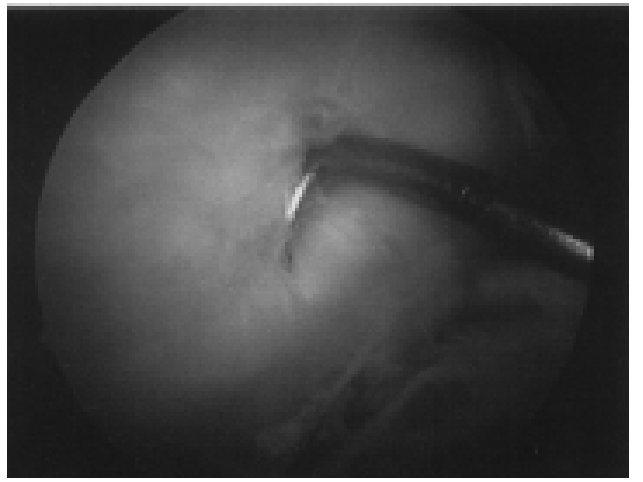

Fig. 3. Arthroscopic view of the depression in the articular surface and fibrillation of the hyaline cartilage around the depression before performing osteochondral autograft transplantation
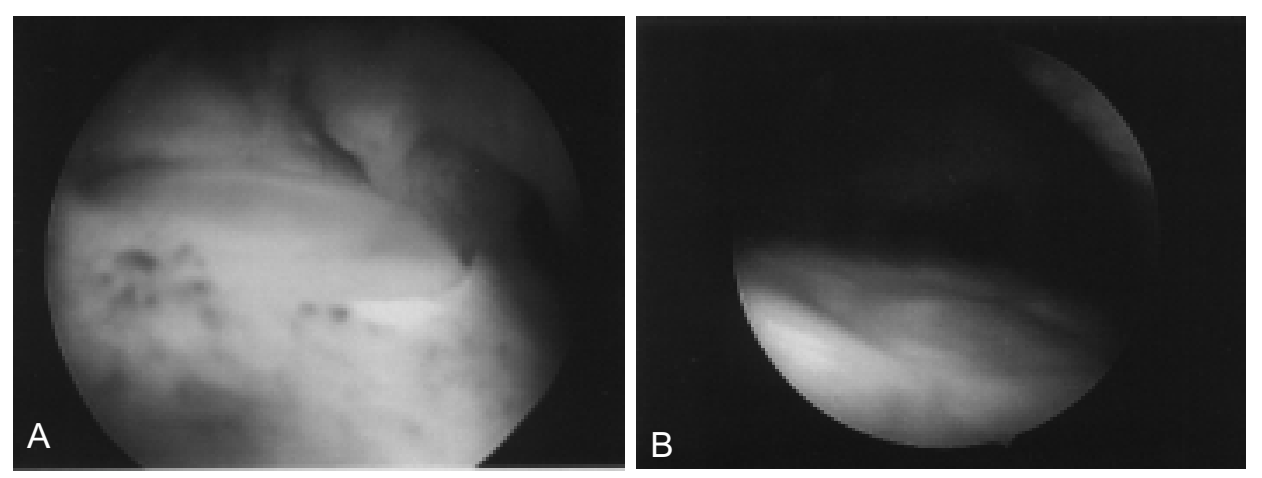

Fig. 4. To prevent haemorrhage, polyglyconate B plugs were used to close the created holes. A: polyglyconate plug at the time of mosaicplasty; B: the same plug after 4 months during control arthroscopy
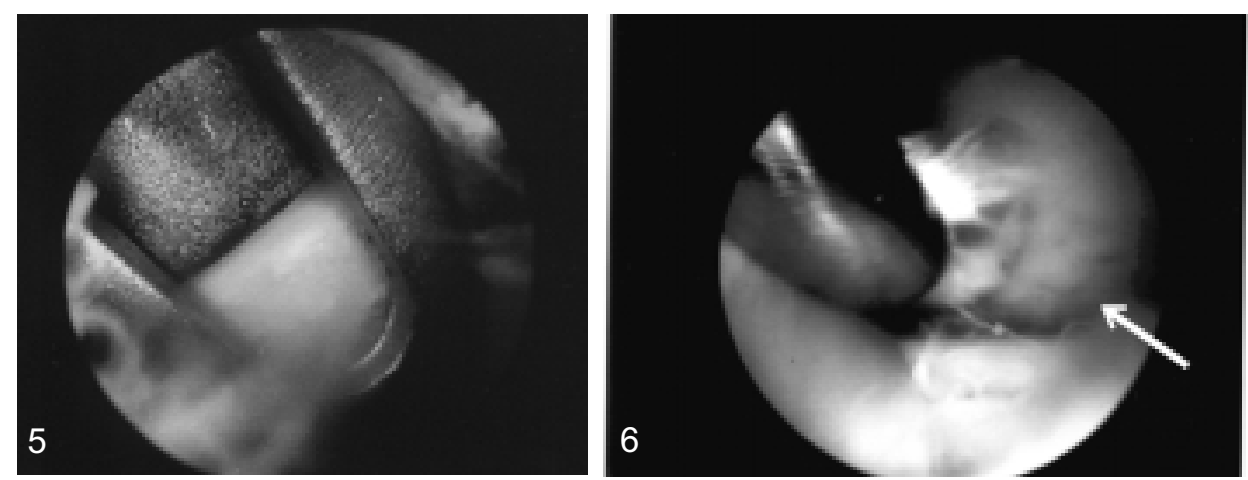

Fig. 5. The graft is delivered into the drilled hole by an adjustable delivery tamp through the chisel guide

Fig. 6. Control arthroscopic view of debridement of the fraying cranial part of the medial meniscus 4 months after surgery. The created new weight-bearing hyaline surface is indicated by an arrow 
About $150 \mathrm{ml}$ of clean transparent synovial fluid was drained from the femoropatellar joint during arthrocentesis. Joint effusion was still present 2 weeks after the operation. For the first month after surgery box rest, and for the second month hand walk was prescribed for the patient. Two months after mosaicplasty paddock exercise and one year postoperatively riding exercise was started.

The lameness appeared to slightly deteriorate for 2 weeks after the operation, but improvement was detected 2 months after surgery. Three months after transplantation the horse regained his previous energetic appearance and body weight. He was galloping freely in the paddock with short and quick turns, without showing signs of pain. In spite of considerable improvement, a grade 1-2 (scale 1-5) mixed lameness was still visible during the control clinical examination. The positivity of the hock-stifle flexion test was reduced, but still present. After the eight-month prescribed postoperative interval, the horse could be used as a breeding stallion again.

\section{Gait analysis}

In order to measure the exact improvement of the lameness, the gait of the horse was analyzed on treadmill (Mustang 2200, Kagra corporation Fahrwangen, Switzerland) before and one year after the operation. Markers were placed on the head, the lateral hoof walls of all limbs, the two tubers coxae, the sacral bone, the metatarsal and tibial bones and the withers (Fig. 7).

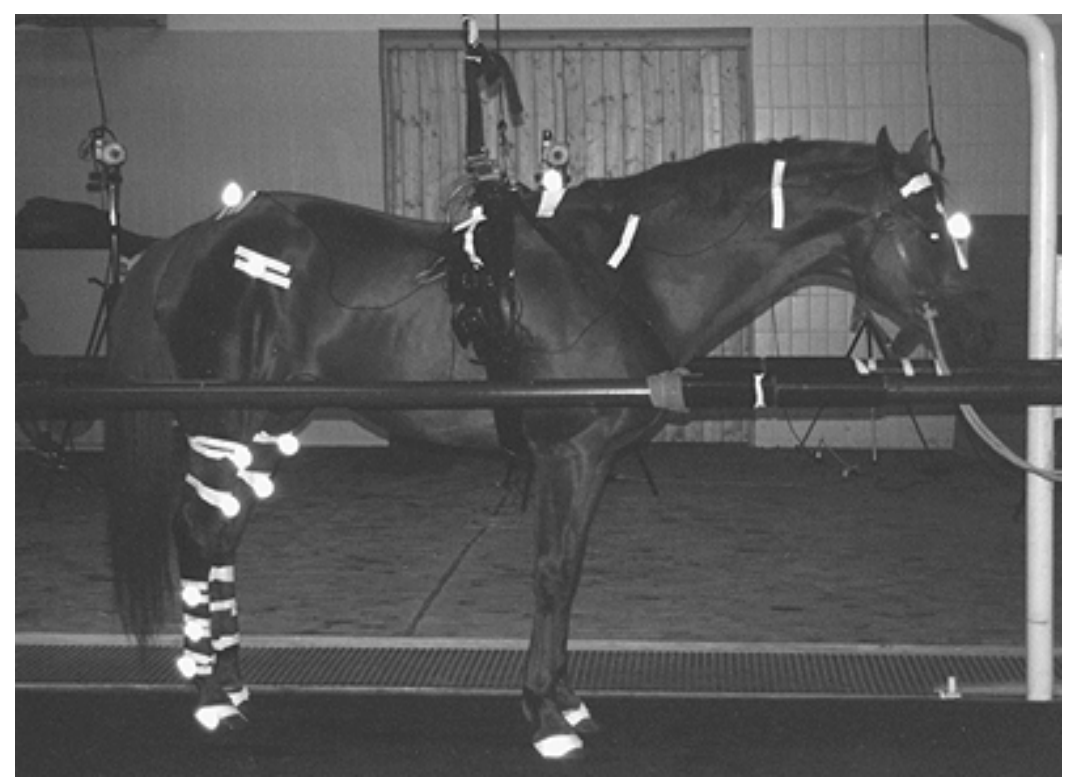

Fig. 7. Markers were placed on the head, the lateral hoof walls of all limbs, the two tubers coxae, the sacral bone, the metatarsal and tibial bones and the withers 
The horse was trained three times on the treadmill for fifteen minutes, in walk and trot (Buchner et al., 1994). Before each measurement, he was allowed to walk and trot on the treadmill for five minutes each to show a stable motion pattern. Recording time was 10 seconds in walk (speed $=1.6 \mathrm{~m} / \mathrm{s}$ ) and trot (speed $=3.6 \mathrm{~m} / \mathrm{s}$ ). The recordings were taken with the 'ExpertVision ${ }^{\mathrm{TM}}$ ' System of Motion Analysis Corporation (Santa Rosa, California). Six cameras (sample rate $120 \mathrm{~Hz}$, three on each side) recorded the motion of the markers. By using the two-dimensional picture of each camera, the three-dimensional co-ordinates of the motion were calculated. The vertical motion of the os sacrum was analysed using the Fourier transformation, and the percentages of symmetry were determined (Peham et al., 1996).

This horse had mixed hindlimb lameness with a disturbed supporting and swinging leg phase. For documentation of the supporting part lowering of the sacral bone, and of the swinging part division of the motion cycle by the ipsilateral hindlimb was measured. The differences of the vertical motion of the sacral bone between left and right stance phase were smaller one year after surgery (Figs $8 \mathrm{~A}$ and $8 \mathrm{~B}$ ), indicating improvement in the supporting part of the lameness.

The mean values of the asymmetry of the vertical motion of the sacral bone in trot were 59\% (SD: 3.9\%) prior to the operation, and $32 \%$ (SD: $6.8 \%$ ) one year after the operation. A significant difference was found between the results of the supporting part of the lameness before and one year after the surgery in walk $(\mathrm{p}<0.01)$ and trot $(\mathrm{p}<0.001)$. However, concerning the swinging part of the hindlimb lameness no significant difference between the cranial phases of stride was detected, indicating that the swinging leg phase did not improve during the one-year postoperative period.

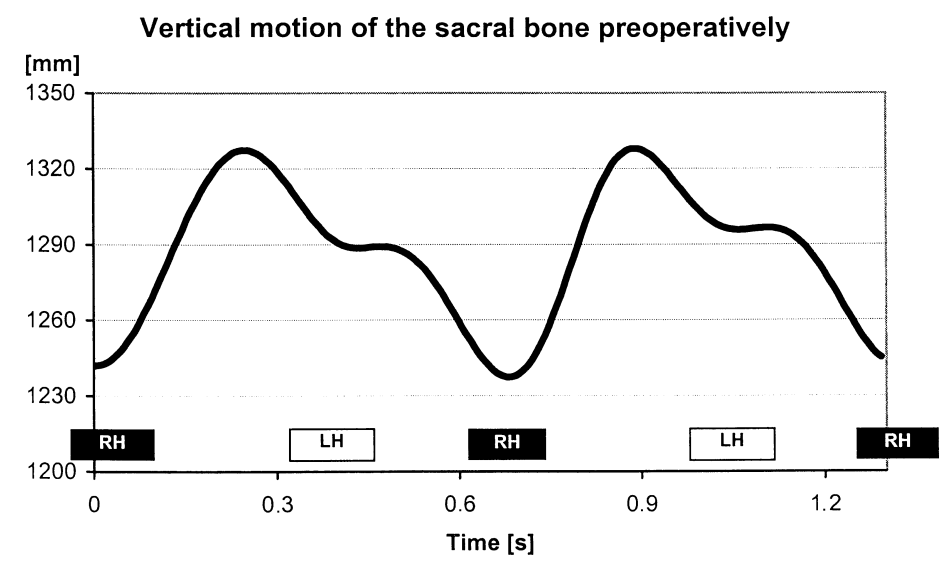

Fig. $8 \mathrm{~A}$. This graph shows the motion of the sacral bone from two motion cycles in trot before the surgery. A severe lameness of the left hindlimb is detectable, because the excursion of the sacral bone during the right stance is much higher than during the left stance 


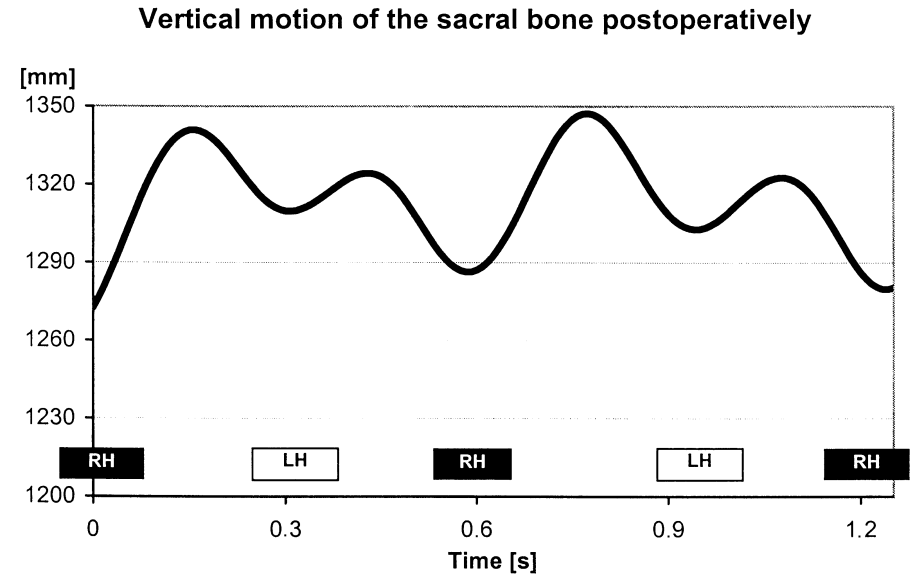

Fig. 8B. This plot represents the motion of the sacral bone from two motion cycles in trot one year after surgery. A mild lameness of the left hindlimb is evident, but the differences of the vertical motion of the sacral bone between left and right stance phases are smaller than before surgery.

$\mathrm{RH}=$ supporting phase of the right hindlimb; $\mathrm{LH}=$ supporting phase of the left hindlimb

\section{Discussion}

Autogenous small cylindrical osteochondral grafts have been successfully used to treat severe localised cartilage defects on the weight-bearing areas of the human knee since 1992 (Matsusue et al., 1993; Hangody, 1994; Bobic, 1996; Hangody, 1997; Hangody et al., 1997b; Hangody et al., 1997c). Experimental works carried out to clarify further details of the healing processes have used dog, sheep, rabbit and horse models (Desjardins et al., 1991; Miniaci, 1999). However, there are no published data about the use of the mosaicplasty technique in veterinary surgery to treat degenerative or cystic lesions of the femoral condyle. There is also no mention in the literature about the application of mosaicplasty to treat osteochondral defects in an animal model.

Mosaicplasty is offered as a safe, effective, and reproducible alternative for the treatment of focal chondral defects of the femoral condyles, patella and talus in humans (Hangody et al., 1997b; Hangody et al., 1997c; Hangody et al., 1997d). Theoretical considerations suggested the use of this technique to treat a cystic lesion of a horse stifle.

Operative techniques previously described for the treatment of subchondral cystic lesions of the medial condyle in the horse involve removal of the overlying hyaline cartilage during curettage of the cyst. An extra-articular approach has also been described without long-term follow-up.

The fact that the articular cartilage overlying the cyst is viable (Jeffcott et al., 1983) can support the operative procedure of this case, as overlying cartilage is only destroyed by drilling the holes for the grafts. 
When transplanting autogenous cancellous bone grafts, only the peripheral $0.2 \mathrm{~mm}$ of the graft is likely to survive transplantation and contribute live cells for new bone formation (Pappas and Beisaw, 1968). Using bone cement for treating the same disease can lead to articular erosion of the opposing articular cartilage (Kold and Hickman, 1984). Therefore, its use is not recommended in cases dependent upon normal function for competitive performance.

Drilling holes through the cyst and surrounding sclerotic bone can stimulate a good healing process around the transplanted grafts. One-block transplantation of autologous osteochondral grafts - as in the human practice - is charged by donor-site morbidity and congruency problems. In the horse a hard, hyalinelike articular gliding surface can be achieved through mosaicplasty as well. To be able to say that the transplanted hyaline cartilage survives also in horses, further proof is required.

No subsidence or loosening of the grafts was seen during follow-up arthroscopy, despite immediate weight-bearing after the operation. In animal trials using German Shepherd dogs, the weight-bearing recipient sites had subsided in a high percentage (Hangody et al., 1997a). Personal experience of the authors involved in the above-mentioned study suggested that for a reliable early weightbearing, correct matching of the length of the recipient tunnels to the graft length is required. This is different from the human practice, where the recipient tunnel is always longer than the graft length.

The procedure does have some limitations. In an adult horse, maximum 5$6(6.5 \mathrm{~mm}$ in diameter and $30-40 \mathrm{~mm}$ in length) grafts can be obtained from the medial border of the trochlea without sacrificing joint function. (This statement is based on clinical experience of the authors in connection with the same operation carried out on ten stifle joints of experimental horses; unpublished data.) The operation is technically demanding. Perpendicular graft insertion remains the most difficult and important aspect to achieve good recipient-site congruity.

Use of 'donor-site plugs' produced from polyglyconate B to minimise postoperative bleeding seemed to be advantageous. These 'donor-site plugs' have never been used in the clinical practice, but promising results of German Shepherd dog trials supported the use of the plugs to avoid excessive postoperative bleeding.

On the other hand, arthroscopic inspection of donor sites demonstrated a good coverage of this area (Fig. 4B). Polyglyconate B - as one of the most popular, modern biodegradable materials in human medicine - has been used intra-articularly as labrum glenoidale anchoring implants, but there is less information about its efficacy as resurfacing material.

Subchondral cystic lesions of the medial femoral condyle are usually diagnosed in horses at three years of age. In this case, clinical signs developed later. According to the owner, the horse had been slightly lame on the same limb before, but the lameness disappeared after a few months of rest. In mild cases the 
overlying hyaline cartilage is viable and intact. In our patient fibrillation of the overlying hyaline cartilage was caused secondarily because of medial meniscus damage.

After performing mosaicplasty, concerning the supporting part of the lameness significant improvement was detected one year after surgery by motion analysis, but the lameness could not be eliminated completely. The medial meniscus damage, which could be treated only partially, might be one reason for the lameness still present one year after operation. Secondarily to meniscus damage, osteophyte formation developed on the medial aspect of the medial tibial condyle. Those arthropathic changes could be responsible for there being no significant difference between the cranial phases of stride concerning the swinging part of the lameness, before and one year after the operation.

The first experiences obtained with mosaicplasty in the horse stifle are encouraging. Meanwhile further three operations have been performed with similar indications. A preliminary report with histological examination of the transplanted areas is in preparation. On the basis of the first observations the use of mosaicplasty technique to treat hyaline cartilage defects in the horse seems to be a promising intervention, but requires further investigation.

\section{Acknowledgements}

Authors are grateful to Ulrike C. B. Schildböck, Andrea Pallos, Zoltán Kárpáti MD and Zoltán Bakos for their assistance.

\section{References}

Bobic, V. (1996): Arthroscopic osteochondral autogenous graft transplantation in anterior cruciate ligament reconstruction: A preliminary clinical study. Knee Surg. Sports Traumatol. Arthrosc. 3, 262-264.

Buchner, H. H. F., Savelberg, H. H. C. M., Schamhardt, H. C., Merkens, H. W. and Barneveld, A. (1994): Habituation of horses to treadmill locomotion. Equine Vet. J. Suppl. 17, 13-15.

Desjardins, M. R., Hurtig, M. B. and Palmer, N. C. (1991): Heterotopic transfer of fresh and cryopreserved autogenous articular cartilage in the horse. Vet. Surg. 20, 434-445.

Evans, L. and Jenny, J. (1970): Surgical and clinical management of subchondral 'bone cysts'. In: Proceedings Am. Assoc. Equine Pract. pp. 195-197.

Hangody, L. (1994): The surgical treatment of knee chondropathy I and II. PhD Thesis. Uzsoki Press, Budapest.

Hangody, L. (1997): Mosaicplasty in the chondral resurfacement. Wellington Knee Meeting, Book of the Lectures. London, UK.

Hangody, L., Kish, G., Kárpáti, Z., Szerb, I., Udvarhelyi, I., Tóth, J., Diószegi, Z. and Kendik, Zs. (1997a): Autogenous osteochondral graft technique for replacing knee cartilage defects in dogs. Orthopedics International Edition 5, 175-181. 
Hangody, L., Kish, G., Kárpáti, Z., Szerb, I. and Udvarhelyi, I. (1997b): Arthroscopic autogenous osteochondral mosaicplasty for the treatment of femoral condylar articular defects. A preliminary report. Knee Surg. Sports Traumatol. Arthrosc. 5, 262-267.

Hangody, L., Kish, G., Kárpáti, Z. and Eberhardt, R. (1997c): Osteochondral plugs: autogenous osteochondral mosaicplasty for the treatment of focal chondral and osteochondral articular defects. Operative Technics in Orthopedics 7, 312-322.

Hangody, L., Kish, G., Kárpáti, Z., Szerb, I. and Eberhardt, R. (1997d): Treatment of osteochondritis dissecans of the talus: use of the mosaicplasty technique - a preliminary report. Foot \& Ankle International 18, 628-634.

Hickman, J., Kold, S. E., Ellis, D. R. and Greenwood, R. E. S. (1984): Use of bone cement in two equine orthopedic cases. Equine Vet. J. 16, 543-545.

Howard, R. D., Mcllwraith, C. W. and Trotter, G. W. (1995): Arthroscopic surgery for subchondral cystic lesions of the medial femoral condyle in horses: 41 cases (1988-1991). J. Am. Vet. Med. Assoc. 206, 842-850.

Jeffcott, L. B. and Kold, S. E. (1982): Clinical and radiological aspects of stifle bone cysts in the horse. Equine Vet. J. 14, 40-46.

Jeffcott, L. B., Kold, S. E. and Melsen, F. (1983): Aspects of the pathology of stifle bone cysts in the horse. Equine Vet. J. 15, 304-311.

Kold, S. E. and Hickman, J. (1983): Use of an autogenous cancellous bone graft in the treatment of subchondral bone cysts in the medial femoral condyle of the horse. Equine Vet. J. 15, 321316.

Kold, S. E. and Hickman, J. (1984): Results of treatment of subchondral bone cysts in the medial condyle of the equine femur with an autogenous cancellous bone graft. Equine Vet. J. 16, 414-418.

Matsusue, Y., Yamainuro, T. and Hama, H. (1993): Arthroscopic multiple osteochondral transplantation to the chondral defect in the knee associated with anterior cruciate ligament disruption: case report. Arthroscopy 9, 318-321.

McIlwraith, C. W. (1990): Diagnostic and surgical arthroscopy of the femoropatellar and femorotibial joints. In: McIlwraith, C. W. (ed.) Diagnostic and Surgical Arthroscopy in the Horse. 2nd edition. Lea \& Febiger, Philadelphia. pp. 113-159.

Miniaci, A. (1999): Articular cartilage transplantation 1999. In: Book of Abstracts of the ISAKOS 1999 Biennial Congress, Washington, DC, USA, May $29^{\text {th }}-$ June $2^{\text {nd }} 1999$, Instructional Course.

Pappas, A. and Beisaw, N. (1968): Bone transplantations; correlation of physical and histological aspects of graft incorporation. Clin. Orthoped. Rel. Res. 61, 79-91.

Peham, Ch., Scheidl, M. and Licka, T. (1996): A method of signal processing in motion analysis of the trotting horse. J. Biomechanics 29, 1111-1114.

Stashak, T. S. (1987): Adam's Lameness in Horses. 4th edition. Lea \& Febiger, Philadelphia. pp. 396-419.

Stewart, B. and Reid, C. F. (1982): Osseous cystlike lesions of the medial femoral condyle in the horse. J. Am. Vet. Med. Assoc. 180, 254-257.

Verschooten, F. and De Moor, A. (1982): Subchondral cystic and related lesions affecting the equine pedal bone and stifle. Equine Vet. J. 14, 47-54.

White, N. A., McIlwraith, C. W. and Allen, D. (1988): Curettage of subchondral bone cysts in medial femoral condyles of the horse. Equine Vet. J. 6, 120-124. 